\title{
FAKTOR YANG BERKONTRIBUSI TERHADAP KEJADIAN STROKE ULANG
}

\author{
${ }^{1}$ Yanti Cahyati, ${ }^{2}$ Ida Rosdiana \\ 1,2, Dosen Jurusan Keperawatan Poltekkes Kemenkes Tasikmalaya
}

\begin{abstract}
Abstrak
Stroke ulang merupakan bahaya yang mengancam penderita stroke yang dapat berakibat fatal dan mengakibatkan kualitas hidup yang lebih buruk dari serangan pertama. Salah satu hal yang menyebabkan terjadinya stroke ulang adalah karena pasien tidak mengendalikan factor resiko yang ada (Misbach \& Kalim, 2006). Faktor resiko yang diketahui bisa dijadikan dasar untuk mencegah terjadinya stroke berulang (Nurhadi, 2005). Pasien yang pernah mengalami stroke $30 \%$ kemungkinan akan mengalami stroke berulang apabila tidak bisa mengendalikan factor resiko stroke. Penelitian ini bertujuan untuk mendapatkan gambaran tentang factor-faktor yang berkontribusi terhadap kejadian stroke ulang pada pasien stroke di RSUD Dr. Soekardjo Kota Tasikmalaya. Desain penelitian yang digunakan adalah deskriptif analitik dengan pendekatan cross sectional, dimana pengukuran variabel-variabelnya dilakukan hanya satu kali. Hasil penelitian menunjukkan terdapat hubungan antara jenis kelamin, kadar kolesterol darah, kadar gula darah dan kebiasaan minum kopi dengan kejadian stroke ulang. Saran diberikan kepada perawat dan responden agar selalu memperhatikan factor-faktor yang bisa menyebabkan terjadinya stroke ulang.
\end{abstract}

Kata Kunci : Stroke ulang

\begin{abstract}
Reccurent Stroke is a danger for stroke patients that can be fatal and result the worse quality of life than the first. One of the things that caused the stroke is because patients do not control the risk factors that exist (Misbach \& Kalim, 2006). The risk factor's can be used as the basis to prevent recurrent stroke (Nurhadi, 2005). Patients who have had a stroke 30\% likely to experience a recurrent stroke if it can not control the risk factors for stroke. This study aimed to get an overview of the factors that contribute to the incidence of stroke in stroke patients in hospital of Tasikmalaya. The study design used is descriptive analytic with cross sectional approach, where the measurement of the variables is done only once. The results showed a correlation between gender, blood cholesterol levels, blood sugar levels and habitual coffee consumption and the incidence of stroke. Advice is given to nurses and the respondent in order to always pay attention to the factors that can lead to stroke again.
\end{abstract}

Keywords : Reccurent stroke

\section{PENDAHULUAN}

Stroke adalah suatu kondisi yang digunakan untuk menjelaskan perubahan neurologik yang disebabkan oleh gangguan dalam sirkulasi darah ke bagian otak (Black \& Hawk, 2009). Stroke adalah penyebab kematian peringkat ketiga penyebab kematian, dengan laju mortalitas $18 \%$ sampai $37 \%$ untuk stroke pertama dan sebesar $62 \%$ untuk stroke selanjutnya. Terdapat kira-kira 2 juta orang bertahan hidup dari stroke yang mempunyai beberapa kecacatan, dari angka ini 40\% memerlukan 
bantuan dalam aktivitas kehidupan seharihari (Smeltzer \& Bare, 2008).

Berdasarkan data dilapangan, angka kejadian stroke meningkat secara dramatis seiring usia. Setiap penambahan usia 10 tahun sejak usia 35 tahun, risiko stroke meningkat dua kali lipat. Sekitar lima persen orang berusia di atas 65 tahun pernah mengalami setidaknya satu kali stroke. Hipertensi sebagai faktor risiko utama prevalensinya semakin meningkat di Indonesia yaitu sekitar 95\%, maka para ahli epidemiologi meramalkan bahwa saat ini dan masa yang akan datang sekitar 12 juta penduduk Indonesia yang berumur diatas 35 tahun mempunyai potensi terkena serangan stroke.Oleh sebab itu, upaya yang komprehensif untuk mengendalikan faktor risiko stroke di masyarakat perlu digalakkan di Indonesia, agar individu yang produktif akan dapat diselamatkan dari serangan stroke apabila dilakukan usaha primer yaitu dengan pengendalian faktor-faktor risiko stroke (Yastroki, 2013).

Kasus stroke di RSUD Dr. Soekardjo

Kota Tasikmalaya jumlahnya terus meningkat dan menempati urutan pertama diantara seluruh kasus sistem persarafan yang ada. Selama tahun 2011 di temukan sebanyak 722 orang pasien stroke yang di rawat di Ruang V RSUD Dr. Soekardjo Kota Tasikmalayasedangkan pada tahun 2012 meningkat menjadi 789 kasus stroke (Rekam Medis RSUD Dr. Soekardjo Kota Tasikmalaya, 2010).

Bahaya yang mengancam penderita stroke adalah stroke berulang yang dapat berakibat fatal dan mengakibatkan kualitas hidup yang lebih buruk dari serangan pertama. Bahkan ada penderita stroke yang mengalami serangan sebanyak $6-7$ kali. Hal ini salah satunya disebabkan karena pasien tersebut tidak mengendalikan factor resiko yang ada (Misbach \& Kalim, 2006).Faktor resiko yang diketahui bisa dijadikan dasar untuk mencegah terjadinya stroke berulang (Nurhadi, 2005).Pasien yang pernah mengalami stroke 30\% kemungkinan akan mengalami stroke berulang apabila tidak bisa mengendalikan factor resiko stroke.
Sebagian besar stroke terjadi akibat kombinasi factor penyebab medis, misalnya peningkatan tekanan darah dan factor penyebab yang berkaitan dengan perilaku misalnya merokok. Penyebab-penyebab ini disebut dengan factor resiko. Sebagian factor resiko dapat dihilangkan atau dikendalikan. Diperkirakan hampir $85 \%$ dari semua kejadian stroke dapat di cegah dengan mengendalikan factor-faktor resiko yang dapat diubah tersebut (Feigin, 2006).

Studi pendahuluan dilakukan di Ruang V RSUD Dr. Soekardjo Kota Tasikmalaya, pada tanggal 10 Januari 2013 ditemukan 10 orang pasien stroke dengan 5 orang diantaranya mengalami stroke ulang. Berdasarkan hasil wawancara beberapa keluarga pasien yang mengalami serangan stroke ulang, 3 orang pasien mengatakan rutin berobat dan diet dengan baik sedangkan 2 orang diantaranya hanya mengunjungi fasilitas kesehatan kalau dirasakan ada keluhan saja, misalnya pusing atau sakit kepala.Penelitian ini bertujuan untuk menjelaskan faktor-faktor yang berkontribusi terhadap kejadian stroke ulang pada pasien stroke di RSUD Dr. Soekardjo Kota Tasikmalaya. Adapun rumumsan masalah penelitian adalah : "Faktor-faktor apa sajakan yang berkontribusi terhadap kejadian stroke ulang pada pasien stroke di RSUD Dr. Soekardjo Kota Tasikmalaya?".

\section{METODE PENELITIAN}

Desain penelitian yang digunakan adalah deskriptif analitik dengan pendekatan cross sectional, dimana pengukuran variabel-variabelnya dilakukan hanya satu kali. Variabel dalam penelitian ini adalah Variabel terikat (Dependent variable) yaitu stroke ulang dan Variabel bebas (Independent variable). Variable bebas dalam penelitian ini adalah factor yang tidak dapat diubah (usia dan jenis kelamin), factor yang dapat diubah (Tekanan Darah, Kadar Kholesterol darah, Kadar Gula Darah, Berat badan, Kebiasaan merokok, Kebiasaan mengkonsumsi alcohol dan Kebiasaan olah raga). 
Populasi dalam penelitian ini adalah semua pasien stroke yang di rawat di Ruang V RSUD Dr. Soekardjo Kota Tasikmalaya pada saat penelitian dilakukan. Pengambilan sampel dilakukan dengan consecutive sampling, dimana semua subjek penelitian yang datang dan memenuhi criteria pemilihan dimasukkan ke penelitian sampai batas waktuya terpenuhi. Berdasarkan kriteria sample yang ditetapkani didapatkan jumlah sample dalam penelitian ini sebanyak 62 orang.Data yang dikumpulkan dalam penelitian ini adalah data primer dan sekunder yang diperoleh dari hasil pengisian kuesioner dan studi dokumentasi catatan rekam medis.

Pengolahan data dilakukan dengan editing, coding, entry data dan cleaning. Data yang telah melalui proses pengolahan selanjutnya akan dianalisis, yang meliputi analisis univariat dan bivariate. Analisis univariat dilakukan untuk mendeskripsikan variabel dependen yaitu jenis stroke dan variabel independen yaitu faktor-faktor yang berhubungan dengan kejadian stroke ulang. Analisis bivariat yang dilakukan disesuaikan dengan data yang ada pada variabel independen dan dependen. Uji bivariat dilakukan dengan menggunakan uji-t independen dan uji chi-square.

\section{HASIL PENELITIAN}

Tabel 1. Distribusi Perbedaan Rata-rata Umur Responden Stroke pertama dan Stroke Ulang di RSUD Dr. Soekardjo Tasikmalaya

\begin{tabular}{ccccc}
\hline Kelompok & Mean & SD & SE & P-Value \\
\cline { 1 - 4 } Stroke Pertama & 62.11 & 8.77 & 1.91 & 0.19 \\
\cline { 1 - 3 } Stroke Ulang & 67.81 & 9.7 & 1.46 & \\
\hline
\end{tabular}

Tabel 2. Distribusi Responden Menurut Jenis Kelamin Pada Pasien Stroke di RSUD Dr. Soekardjo Kota Tasikmalaya

\begin{tabular}{|c|c|c|c|c|c|c|c|c|}
\hline \multirow{3}{*}{$\begin{array}{l}\text { Jenis } \\
\text { Kelamin }\end{array}$} & \multicolumn{4}{|c|}{ Jenis stroke } & \multirow{2}{*}{\multicolumn{2}{|c|}{ TOTAL }} & \multirow{3}{*}{$\begin{array}{c}\text { OR } \\
(95 \% \mathrm{Cl})\end{array}$} & \multirow{3}{*}{ P-Value } \\
\hline & \multicolumn{2}{|c|}{ Stroke Pertama } & \multicolumn{2}{|c|}{ Stroke Ulang } & & & & \\
\hline & $\mathbf{N}$ & $\%$ & $\mathbf{N}$ & $\%$ & $\mathbf{N}$ & $\%$ & & \\
\hline Laki-laki & 10 & 33.3 & 20 & 66.7 & 30 & 100 & $\begin{array}{c}0,15 \\
0,036-0,371\end{array}$ & 0,001 \\
\hline Perempuan & 26 & 81.2 & 6 & 18.8 & 32 & 100 & & \\
\hline JUMLAH & 36 & 58.1 & 26 & 41.9 & 62 & 100 & & \\
\hline
\end{tabular}

Tabel 3. Distribusi Responden Menurut Tekanan Darah Pada Pasien Stroke di RSUD Dr. Soekardjo Kota Tasikmalaya

\begin{tabular}{|c|c|c|c|c|c|c|c|c|}
\hline \multirow{3}{*}{$\begin{array}{c}\text { Tekanan } \\
\text { Darah }\end{array}$} & \multicolumn{4}{|c|}{ Jenis stroke } & \multirow{2}{*}{\multicolumn{2}{|c|}{ TOTAL }} & \multirow{3}{*}{$\begin{array}{c}\text { OR } \\
(95 \% \mathrm{Cl})\end{array}$} & \multirow{3}{*}{ P-Value } \\
\hline & \multicolumn{2}{|c|}{ Stroke Pertama } & \multicolumn{2}{|c|}{ Stroke Ulang } & & & & \\
\hline & $\mathbf{N}$ & $\%$ & $\mathbf{N}$ & $\%$ & $\mathbf{N}$ & $\%$ & & \\
\hline Terkontrol & 0 & 0 & 1 & 100 & 1 & 100 & $1,80-3,30$ & 0,419 \\
\hline Tidak terkontrol & 36 & 59.0 & 25 & 41.0 & 61 & 100 & & \\
\hline JUMLAH & 36 & 59.0 & 26 & 41.9 & 62 & 100 & & \\
\hline
\end{tabular}


Tabel 4. Distribusi Responden Menurut Kadar Kolesterol Pada

Pasien Stroke di RSUD Dr. Soekardjo Kota Tasikmalaya

\begin{tabular}{|c|c|c|c|c|c|c|c|c|}
\hline \multirow{3}{*}{ Kholesterol } & \multicolumn{4}{|c|}{ Jenis stroke } & \multirow{2}{*}{\multicolumn{2}{|c|}{ TOTAL }} & \multirow{3}{*}{$\begin{array}{c}\text { OR } \\
(95 \% \mathrm{Cl})\end{array}$} & \multirow{3}{*}{ P-Value } \\
\hline & \multicolumn{2}{|c|}{ Stroke Pertama } & \multicolumn{2}{|c|}{ Stroke Ulang } & & & & \\
\hline & $N$ & $\%$ & $N$ & $\%$ & $N$ & $\%$ & & \\
\hline Terkontrol & 21 & 47.7 & 23 & 52.3 & 44 & 100 & $0,046-0,721$ & 0,022 \\
\hline $\begin{array}{c}\text { Tidak } \\
\text { terkontrol }\end{array}$ & 15 & 83.3 & 3 & 16.7 & 18 & 100 & & \\
\hline JUMLAH & 36 & 58.1 & 26 & 41.9 & 62 & 100 & & \\
\hline
\end{tabular}

Tabel 5. Distribusi Responden Menurut Kadar Gula Darah Pada Pasien Stroke di RSUD Dr. Soekardjo Kota Tasikmalaya

\begin{tabular}{|c|c|c|c|c|c|c|c|c|}
\hline \multirow{3}{*}{ Gula Darah } & \multicolumn{4}{|c|}{ Jenis stroke } & \multirow{2}{*}{\multicolumn{2}{|c|}{ TOTAL }} & \multirow{3}{*}{$\begin{array}{c}\text { OR } \\
(95 \% \mathrm{Cl})\end{array}$} & \multirow{3}{*}{ P-Value } \\
\hline & \multicolumn{2}{|c|}{ Stroke pertama } & \multicolumn{2}{|c|}{ stroke ulang } & & & & \\
\hline & $\mathbf{N}$ & $\%$ & $\mathbf{N}$ & $\%$ & $\mathbf{N}$ & $\%$ & & \\
\hline Terkontrol & 28 & 51.9 & 26 & 48.1 & 54 & 100 & $0,40-0,70$ & 0,016 \\
\hline Tidak terkontrol & 8 & 100 & 0 & 0 & 8 & 100 & & \\
\hline JUMLAH & 36 & 58.1 & 26 & 41.9 & 62 & 100 & & \\
\hline
\end{tabular}

Tabel 6. Distribusi Responden Menurut Berat Badan Pada

Pasien Stroke di RSUD Dr. Soekardjo Kota Tasikmalaya

\begin{tabular}{|c|c|c|c|c|c|c|c|c|}
\hline \multirow{3}{*}{ Berat Badan } & \multicolumn{4}{|c|}{ Jenis stroke } & \multirow{2}{*}{\multicolumn{2}{|c|}{ TOTAL }} & \multirow{3}{*}{$\begin{array}{c}\text { OR } \\
(95 \% \mathrm{Cl})\end{array}$} & \multirow{3}{*}{ P-Value } \\
\hline & \multicolumn{2}{|c|}{ Stroke pertama } & \multicolumn{2}{|c|}{ stroke ulang } & & & & \\
\hline & $\mathbf{N}$ & $\%$ & $\mathbf{N}$ & $\%$ & $\mathbf{N}$ & $\%$ & & \\
\hline Terkontrol & 19 & 82.6 & 4 & 17.4 & 23 & 100 & $1,76-21,46$ & 0,6 \\
\hline Tidak terkontrol & 17 & 43.6 & 22 & 56.4 & 39 & 100 & & \\
\hline JUMLAH & 36 & 58.1 & 26 & 41.9 & 62 & 100 & & \\
\hline
\end{tabular}

Tabel 7. Distribusi Responden Menurut Kebiasaan Merokok Pada Pasien Stroke di RSUD Dr. Soekardjo Kota Tasikmalaya

\begin{tabular}{|c|c|c|c|c|c|c|c|c|}
\hline \multirow{3}{*}{$\begin{array}{c}\text { Kebiasaan } \\
\text { merokok }\end{array}$} & \multicolumn{4}{|c|}{ Jenis stroke } & \multirow{2}{*}{\multicolumn{2}{|c|}{ TOTAL }} & \multirow{3}{*}{$\begin{array}{c}\text { OR } \\
(95 \% \mathrm{Cl})\end{array}$} & \multirow{3}{*}{ P-Value } \\
\hline & \multicolumn{2}{|c|}{ Stroke pertama } & \multicolumn{2}{|c|}{ stroke ulang } & & & & \\
\hline & $\mathbf{N}$ & $\%$ & $\mathbf{N}$ & $\%$ & $\mathbf{N}$ & $\%$ & & \\
\hline tidak & 23 & 76.7 & 7 & 23.3 & 30 & 100 & $1,60-1,45$ & 0,09 \\
\hline ya & 13 & 40.6 & 19 & 59.4 & 32 & 100 & & \\
\hline JUMLAH & 36 & 58.1 & 26 & 41.9 & 62 & 100 & & \\
\hline
\end{tabular}


Tabel 8. Distribusi Responden Menurut Kebiasaan Minum Kopi Pada Pasien Stroke di RSUD Dr. Soekardjo Kota Tasikmalaya

\begin{tabular}{|c|c|c|c|c|c|c|c|c|}
\hline \multirow{3}{*}{$\begin{array}{l}\text { Kebiasaan } \\
\text { minum kopi }\end{array}$} & \multicolumn{4}{|c|}{ Jenis stroke } & \multicolumn{2}{|c|}{ TOTAL } & \multirow{3}{*}{$\begin{array}{c}\text { OR } \\
(95 \% \mathrm{Cl})\end{array}$} & \multirow{3}{*}{ P-Value } \\
\hline & \multicolumn{2}{|c|}{ Stroke pertama } & \multicolumn{2}{|c|}{ stroke ulang } & & & & \\
\hline & $\mathbf{N}$ & $\%$ & $\mathbf{N}$ & $\%$ & $\mathbf{N}$ & $\%$ & & \\
\hline Tidak & 20 & 90.9 & 2 & 9.1 & 22 & 100 & $3,07-7,32$ & 0,0005 \\
\hline Ya & 16 & 40 & 24 & 60 & 40 & 100 & & \\
\hline JUMLAH & 36 & 58.1 & 26 & 41.9 & 62 & 100 & & \\
\hline
\end{tabular}

Tabel 9. Distribusi Responden Menurut Kebiasaan Mengkonsumsi Alkohol Pada Pasien Stroke di RSUD Dr. Soekardjo Kota Tasikmalaya

\begin{tabular}{ccccccc}
\hline \multirow{2}{*}{$\begin{array}{c}\text { Kebiasaan } \\
\text { mengkonsumsi } \\
\text { alcohol }\end{array}$} & \multicolumn{4}{c}{ Jenis stroke } & \multicolumn{2}{c}{ TOTAL } \\
\cline { 2 - 5 } & \multicolumn{2}{c}{ Stroke pertama } & stroke ulang & & \\
\cline { 2 - 6 } & $\mathbf{N}$ & $\%$ & $\mathbf{N}$ & $\%$ & $\mathbf{N}$ & $\%$ \\
\hline Tidak & 36 & 58.1 & 26 & 41.9 & 62 & 100 \\
\hline Ya & 0 & 0 & 0 & 0 & 0 & 0 \\
\hline JUMLAH & 36 & 58.1 & 26 & 41.9 & 62 & 100 \\
\hline
\end{tabular}

Tabel 10. Distribusi Responden Menurut Kebiasaan Olah Raga Pada Pasien Stroke di RSUD Dr.Soekardjo Kota Tasikmalaya

\begin{tabular}{|c|c|c|c|c|c|c|c|c|}
\hline \multirow{3}{*}{$\begin{array}{c}\text { Kebiasaan olah } \\
\text { raga }\end{array}$} & \multicolumn{4}{|c|}{ Jenis stroke } & \multirow{2}{*}{\multicolumn{2}{|c|}{ TOTAL }} & \multirow{3}{*}{$\begin{array}{c}\text { OR } \\
(95 \% \mathrm{Cl})\end{array}$} & \multirow{3}{*}{ P-Value } \\
\hline & \multicolumn{2}{|c|}{ Stroke pertama } & \multicolumn{2}{|c|}{ stroke ulang } & & & & \\
\hline & $\mathbf{N}$ & $\%$ & $\mathbf{N}$ & $\%$ & $\mathbf{N}$ & $\%$ & & \\
\hline ya & 1 & 50 & 1 & 50 & 2 & 100 & $0,04-11,9$ & 1,00 \\
\hline tidak & 35 & 58.3 & 25 & 41.7 & 60 & 100 & & \\
\hline JUMLAH & 36 & 58.1 & 26 & 41.9 & 52 & 100 & & \\
\hline
\end{tabular}

\section{PEMBAHASAN}

Hasil penelitian menunjukkan tidak ada hubungan antara umur dengan kejadian stroke ulang. Hal ini berbeda dengan konsep yang menyatakan bahwa usia berpengaruh terhadap kejadian stroke dan stroke ulang. Peneliti menyimpulkan bahwa tidak adanya kaitan antara umur dengan kejadian stroke ulang bisa disebabkan oleh terkontrolnya factor-faktor resiko yang menyebabkan responden mengalami stroke ulang.

Berdasarkan hasil penelitian ini, lakilaki mempunyai peluang lebih besar untuk mengalami stroke ulang. Hampir semua responden memiliki tekanan darah yang tidak terkontrol, hasil ini bermakna untuk menggambarkan ketidakpatuhan responden untuk mengontrol tekanan darah sehingga mengakibatkan kejadian stroke berulang. Ketidakpatuhan ini akanmengakibatkan tekanan darah tidak terkontrol/meningkat sehingga aliran darah ke otak akan terganggu.

Hasil penelitian menunjukkan bahwa tidak ada hubungan antara tekanan darah yang terkontrol dengan kejadian serangan stroke berulang. Hal ini dapat terjadi karena 
responden yang tidak patuh tersebut masih mengontrol tekanan darah dan minum obat antihipertensi bila merasa sakit kepala. Tindakan yang dilakukan oleh responden tersebut dapat memperlambat kerusakan dinding pembuluh darah sehingga aliran darah ke otak masih adekuat.

Sebagian besar responden memiliki kadar kolesterol darah yang terkontrol. Hal ini merupakan salah satu hal baik, karena kolesterol yang terkontrol dengan baik dan berada dalam rentang normal akan memberikan peluang yang sangat baik untuk tidak terjadinya stroke ulang. Hasil analisis menunjukkan bahwa terdapat hubungan antara kadar cholesterol darah yang terkontrol dengan kejadian stroke ulang. Hal ini sejalan dengan teori yang menunjukkan bahwa kolesterol berpengaruh terhadap terjadinya peningkatan tekanan darah.

Sebagian besar responden memiliki kadar gula darah yang terkontrol. Hal ini merupakan prognosa yang baik karena gula darah yang terkontrol akan menyebabkan peluang untuk mengalami stroke ulang. Hasil analisis bivariat menunjukkan bahwa ada hubungan antara gula darah yang terkontrol dengan kejadian serangan stroke berulang. Hal ini sejalan dengan teori yang menunjukkan bahwa terdapat hubungan antara kejadian stroke ulang dengan gula darah yang terkontrol.

Sebagian besar responden memiliki berat badan yang tidak terkontrol. Hasil analisis bivariat menunjukkan bahwa tidak ada hubungan antara berat badan yang terkontrol dengan kejadian serangan stroke berulang. Tidak adanya hubungan antara kepatuhan mengontrol berat badan dengan kejadian stroke berulang pada penelitian ini dapat terjadi karena sebagian besar responden memiliki berat badan normal.

Menurut (Feigin, 2006), merokok meningkatkan risiko terkena stroke empat kali lipat. Hal ini berlaku bagi semua jenis rokok (sigaret, pipa atau cerutu) dan untuk semua tipe stroke, terutama perdarahan subarakhnoid dan stroke non hemoragik. Hasil analisis bivariat menunjukkan bahwa tidak ada hubungan antara kebiasaan merokok dengan kejadian serangan stroke berulang. Tidak adanya hubungan antara kebiasaan merokok dengan kejadian stroke berulang pada penelitian ini dapat terjadi karena jumlah terbesar responden yang mengalami kejadian stroke berulang tidak memiliki kebiasaan merokok sebelum kejadian stroke berulang.

Semua responden pada penelitian ini tidak memiliki kebiasaaan mengkonsumsi alcohol. Hasil analisis menunjukkan bahwa tidak ada hubungan antara kebiasaan mengkonsumsi alcohol dengan kejadian stroke ulang. Alkohol memiliki sejumlah dampak buruk yang sangat berbahaya terutama bagi kesehatan. Darah yang mengandung alkohol dapat merusak jaringan tubuh terutama hati, menyebabkan trombosis, memicu stres, menyebabkan arteri menjadi tidak lentur, mengganggu ritme sirkardian tubuh terutama menyebabkan gangguan tidur, menurunkan fungsi memori, dan meningkatkan kadar gula dan lemak darah. Kurangnya aktifitas dan olah raga bisa menjadi salah satu factor pemicu kejadian stroke ulang.

\begin{tabular}{llr}
\multicolumn{1}{c}{ Dari hasil penelitian ini } & peneliti \\
memberikan rekomendasi & kepada \\
responden Hendaknya pasien & selalu \\
mengontrol factor-faktor yang bisa & birol \\
menyebabkan terjadinya stroke ulang \\
dengan cara berperilaku sehat sesuai yang \\
dianjukan oleh tenaga kesehatan.
\end{tabular}

\section{KESIMPULAN}

Berdasarkan hasil penelitian ini factorfaktor yang secara statistic berhubungan dengan kejadian stroke ulang adalah jenis kelamin, kadar cholesterol darah, kadar gula darah da kebiasaan minum kopi.

\section{DAFTAR PUSTAKA}

American Heart association. (2010). Heart deases and stroke statistic: our guide to current statistics and the suplement to our heart and stroke fact- 2010 update.http://www. americanheart.org. Diakses pada tanggal 14 Maret 2011. 
Ariawan, I. (1998). Besar dan metode sampel pada penelitian kesehatan. Jakarta : Jurusan Biostatistik dan kependudukan Fakultas Kesehatan Masyarakat, Universitas Indonesia.

Arikunto, S. (2010). Prosedur penelitian: suatu pendekatan praktik. Jakarta: Rhineka Cipta.

Black,J.M., \& Hawks,J.H., (2009) Medical surgical nursing clinical management for positive outcomes, $8^{\text {th }}$ Edition. St Louis Missouri : Elsevier Saunders.

Hastono, S,P,. (2007). Analisis data kesehatan. Depok : Fakultas Kesehatan Masyarakat Universitas Indonesia.

Kozier, B., et al. (2008). Kozier and Erb'sFundamentals of nursing, concept, process and practic, eighth edtion. New Jersey : Pearson Education.

Kozier,B. et al. (2004). Techniques in clinical nursing $5^{\text {th }}$ edition. Canada : Cummings Publishing Company.

Lemone,P., \& Burke,K. (2004). Medical Surgical Nursing Critical Thinking in Client Care. Third Edition. New Jersey: Pearson Education.

Lewis (2007). Medical surgical nursing: assessment \& management of clinical problem. $7^{\text {th }}$ edition. St.Louis: Missouri.Mosby-Year Book, Inc

Lewis, G. N., \& Byblow, W. D. (2004). Neurophysiological and behavioural adaptations to a bilateral training intervention in individuals following stroke. Clinical Rehabilitation, 18(1), 48-59.

Polit, D.F., \& Beck, C.T. (2008). Essensials of nursing research: methods, appraisal and utilization $\left(6^{\text {th }} \mathrm{Ed}\right)$. Philadelphia: Lippincott Williams \& Walkins.

Potter, A.P., \& Perry, A. (2006). Fundamental of nursing. $4^{\text {th }}$ edition. St.Louis Missouri:Mosby-Year Book, Inc.

Price, S.A., \& Wilson, L.M. (2006) Patofisiologi konsep klinis proses penyakit Edisi 6. EGC. Jakarta.

Rekam Medis RSUD Dr. Soekardjo Kota Tasikmalaya, (2012). Laporan kasus rawat inap dan rawat jalan RSUD Dr. Soekardjo Kota Tasikmalaya.

Sastroasmoro, S., \& Ismael, S. (2010). Dasar-dasar metodologi penelitian klinis. Edisi ke-3. Jakarta : Sagung Seto.

Smeltzer, S.C., Bare, B.G., Hinkle, J.L. \& Cheever, K.H. (2008) Brunner \& Suddarth's Textbook of medicalsurgical nursing. 11th Edition. Philadelphia: Lippincott William \& Wilkins.

Sugiyono. (2010). Metode penelitian kuantitatif, kualitatif dan $R$ \& $D$. Bandung : Alfabeta.

Yastroki. (2007). Indonesia, negara dengan jumlah penderita stroke terbesar di Asia.http://www.yastroki.or.id. Diperoleh tanggal 5 Desember 2010. 